NASA

Technical Memorandum 106713

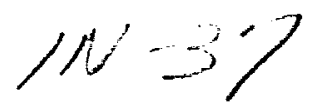

19870
Army Research Laboratory Technical Report ARL-TR-306

\title{
Computerized Design of Low-Noise Face-Milled Spiral Bevel Gears
}

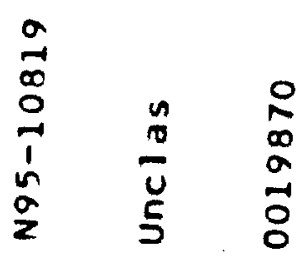

Faydor L. Litvin

University of Illinois at Chicago

Chicago, Illinois

Yi Zhang

University of Michigan at Dearborn

Dearborn, Michigan

and

Robert F. Handschuh

Vehicle Propulsion Directorate

U.S. Army Research Laboratory

Lewis Research Center

Cleveland, Ohio

Prepared for the

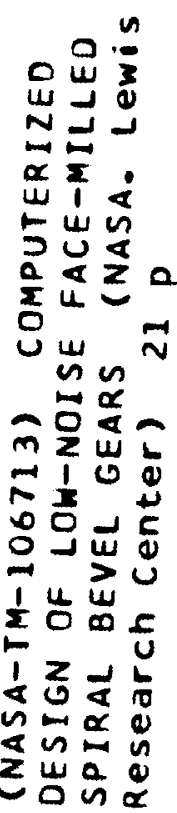

23rd Mechanisms Conference

sponsored by the American Society of Mechanical Engineers

Minneapolis, Minnesota, September 11-14, 1994

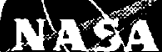

National Aeronautics and

Space Administration

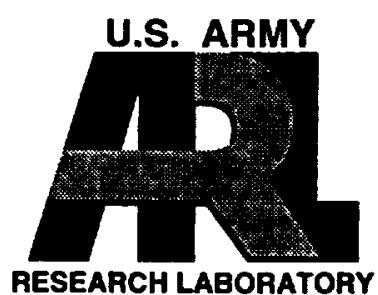


$-5$ 
Computerized Design of Low-Noise Face-Milled Spiral Bevel Gears

\author{
Faydor L. Litvin \\ University of Illinois at Chicago \\ Chicago, Illinois \\ Yi Zhang \\ University of Michigan at Dearborn \\ Dearborn, Michagan \\ Robert F. Handschuh \\ Army Research Laboratory, Vehicle Propulsion Directorate \\ NASA Lewis Research Center \\ Cleveland, Ohio
}

\begin{abstract}
An advanced design methodology is proposed for the face-milled spiral bevel gears with modified tooth surface geometry that provides a reduced level of noise and has a stabilized bearing contact. The approach is based on the local synthesis of the gear drive that provides the "best" machine-tool settings. The theoretical aspects of the local synthesis approach are based on the application of a predesigned parabolic function for absorption of undesirable transmission errors caused by misalignment and the direct relations between principal curvatures and directions for mating surfaces. The meshing and contact of the gear drive is synthesized and analyzed by a computer program. The generation of gears with the proposed geometry design can be accomplished by application of existing equipment. A numerical example that illustrates the proposed theory is presented.
\end{abstract}

\title{
1. Introduction
}

Spiral bevel gears have found a broad application in gear transmissions, particularly in high-speed helicopter transmissions. The most important criteria of the quality of meshing of spiral bevel gears applied in high-speed transmissions are low noise and stable bearing contact that must be obtained even under some misalignments.

The analysis of quality of gear drives is based on computerized simulation of meshing and contact of gear drives by Tooth Contact Analysis (TCA) computer programs. The TCA algorithm has been proposed by Litvin and then applied for spiral bevel gears by 
Litvin and Go [1]. Commercially developed TCA computer programs for the analysis of meshing of spiral bevel gears and hypoid gears are also available $[2,3,4]$. Later similar programs for hypoid gear drives have been developed as well by Litvin and Gutman [5].

TCA programs are valuable but are designed for the analysis of meshing of gear drives and not for their synthesis. Although the TCA programs enable investigation of the influence of machine-tool setting variation on the quality of meshing and contact, it would be very difficult to determine the "best" machine-tool settings by application of the TCA approach. Litvin and Gutman $[5,6]$ have developed the method of local synthesis of gear drives. This approach permits the determination of the "best" machine-tool settings considering the conditions of meshing and contact at the mean contact point and within its neighborhood. Usually, the local synthesis approach may provide the set of machine-tool settings, and the role of TCA is to verify the acceptance of the obtained settings, estimate the influence of misalignment and correct (usually slightly) the previously obtained machine-tool settings.

This paper has used both ideas (the local synthesis and TCA approaches) for the design of spiral bevel gears with substantially reduced level of noise and a stabilized bearing contact. These goals have been achieved by application of the following ideas:

Stage 1. The machine-tool settings for the generation of the gear may be considered as given in the local synthesis. The gear machine-tool settings are calculated according to the spiral angle of the gear member determined in the design of blank. The improvement of meshing and contact can be accomplished by the determination of proper machine-tool settings for the pinion only.

It was assumed that the gear is generated by the duplex method (both tooth sides are generated simultaneously) and the pinion tooth sides are generated seperately.

Stage 2. The application of local synthesis method is based on the following procedures:

Step 1: The mean contact point $M$ is chosen on the gear tooth surface. The equations of gear tooth surface $\Sigma_{2}$ are known since the gear machine-tool settings have been determined already.

Step 2: The tangency of four surfaces $-\Sigma_{t 2}$ (gear generating surface), $\Sigma_{t 1}$ (pinion 
generating surface), $\Sigma_{2}$ (gear surface), and $\Sigma_{1}$ (pinion surface) - at the point $M$ is provided.

Step 3: The conditions of meshing and contact of surfaces $\Sigma_{1}$ and $\Sigma_{2}$ at $M$ are considered, and the following requirements are observed: (i) the gear ratio $m_{21}\left(\phi_{1}\right)=N_{1} / N_{2}$ at M ( $N_{1}$ and $N_{2}$ are the numbers of pinion and gear teeth); (ii) The derivative $m_{21}^{\prime}\left(\phi_{1}\right)=$ $\frac{\partial}{\partial \phi_{1}}\left[m_{21}\left(\phi_{1}\right)\right]\left(\phi_{1}\right.$ is the rotation of the pinion) must satisfy the requirement of minimization of transmission errors; (iii) the designated magnitude of the major axis of the instantaneous contact ellipse at $M$ must be observed; and (iv) the designated orientation of the tangent to the contact path at $M$ must be observed as well.

The output of the computerized procedure discussed in Stage 2 are the princinpal curvatures and directions of the pinion surface at point $M$.

Stage 3. Surfaces $\Sigma_{t 1}$ and $\Sigma_{1}$ of the generating tool and the pinion tooth are considered in contact, and the instantaneous line of contact passes through point $M$. The principal curvatures and directions at point $M$ of the head-cutter surface $\Sigma_{t 1}$ are determined.

Stage 4. The machine-tool settings of the head-cutter $\Sigma_{t 1}$ with respect to the pinion tooth surface $\Sigma_{1}$ are determined.

Stage 5. The equations of pinion tooth surface are derived considering the machinetool settings of the head-cutter are known with respect to $\Sigma_{1}$.

Stage 6. The TCA program is developed considering the conditions of continuous tangency of tooth surfaces $\Sigma_{1}$ and $\Sigma_{2}$. The influence of misalignment of the gear drive on the conditions of meshing and contact can be investigated at this stage.

The following ideas are the theoretical basis of the work in this paper: (i) a predesigned parabolic function of transmission errors can absorb a linear discontinuous function of transmission errors caused by the misalignment of the drive; and (ii) direct relations between the principal directions and curvatures of the two surfaces being in line contact or in point contact can be established.

The theoretical solutions have been tested by computerized simulation of meshing and contact and by direct experimental test of a prototype gear drive. A comparative test for the service life and level of noise has been performed based on a previously existing design and the new design proposed by Litvin and Zhang [9]. The new design reduced the level of noise by 12-18 decibels [11] and the gear drive successfully passed scoring and pitting 
test.

The production of spiral bevel gears with the new design can be accomplished using conventional gear grinding equipment but with simpler machine-tool settings as there is no need for the tilt of the head-cutter or the modified roll (variation of motions) in the process of generation. The paper is illustrated with a numerical example.

\section{Generation Of Pinion And Gear Surfaces}

We use the following coordinate systems while considering the process for pinion and gear tooth generation: (i) the fixed one, $S_{m i}(i=1,2)$, that is rigidly connected to the frame of the cutting machine, and (ii) the movable systems $S_{c i}$ and $S_{i}$ that are rigidly connected to the cradle and the pinion (gear) being generated (Fig. 1). The tool (head-cutter) is mounted on the cradle and coordinate system $S_{t i}$ of the tool is rigidly connected to the cradle coordinate system $S_{c i}$. The pinion (gear) being generated and the cradle perform related rotational motions about axes $x_{i}$ and $z_{m i}$, respectively. The rotation of the headcutter about the $z_{t i}$ axis provides the desired velocity of cutting and is not related to the process of tooth surface generation. The subscripts $i=1,2$ in designations $S_{m i}, S_{t i}$, and $S_{i}$ designate the pinion and the gear, respectively.

The machine-tool settings are represented by the following constant parameters (Fig. 1): $E_{m i}$ (the blank offset); $\gamma_{m i}$ (the machine root angle); $X_{b i}$ (the sliding base); $X_{p i}$ (the machine center to back); $S_{r i}$ (the radial setting of the head- cutter); $r_{c i}$ (the cutter point radius); $q_{i}$ (the initial cradle angle); $\alpha_{i}$ (the cutter blade angle, Fig. 2); $R_{a i}$ (the ratio of roll - the ratio of angular velocities of the cradle and the workpiece).

The tool (head-cutter) generating surface (Fig. 2) may be represented in $S_{t i}$ by the vector function

$$
\mathbf{r}_{t i}\left(s_{i}, \theta_{i}\right)
$$

where, $\left(s_{i}, \theta_{i}\right)$ are the surface coordinates (the Gaussian coordinates). For the gear, we consider the design parameters of the tools, $\alpha_{2}$ and $r_{c 2}$, and the remaining machine-tool settings as given (they are determined according to the spiral angle of the gear). However, 
all the machine-tool settings for the pinion are not known, and they have to be determined by using the procedure of local synthesis.

The generated surface $\Sigma_{i}$ can be determined as the envelope to the family of tool surfaces generated in $S_{i}$ when the head-cutter and the gear (or pinion) perform the related motions. Surface $\Sigma_{i}$ is represented in $S_{i}$ in three-parameter form (but with related parameters) by the following equations:

$$
\begin{gathered}
\mathbf{r}_{i}\left(s_{i}, \theta_{i}, \phi_{i}\right)=M_{i t i}\left(\phi_{i}\right) \mathbf{r}_{t i}\left(s_{i}, \theta_{i}\right) \\
\mathbf{n}_{j}^{t i} \cdot \mathbf{v}_{j}^{t i, i}=f\left(s_{i}, \theta_{i}, \phi_{i}\right)=0
\end{gathered}
$$

Here, $M_{i t i}\left(\phi_{1}\right)$ is the matrix for coordinate transformation; $\mathbf{n}^{t i}$ and $\mathbf{v}^{t i, i}$ are the surface unit normal and the relative velocity in generation motion; Subscript $j$ is equal to $m_{i}, t_{i}, i$ and this designation indicates that vectors of the scalar product in equation (3) can be represented in any of the three coordinate systems mentioned above. Equation (3) is called the equation of meshing $[6,7]$.

Taking into account that $s_{i}$ is a linear parameter in equation (3), it can be easily eliminated and the gear tooth surface can be represented in two-parameter form by the vector function:

$$
\mathbf{r}_{2}\left(\theta_{2}, \phi_{2}\right)
$$

Similarly the pinion tooth surface can be represented, but the parameters of the machine-tool settings are still not determined until the procedure of local synthesis will be accomplished. The mean contact point on surface $\Sigma_{2}$ is usually chosen as the mean point of $\Sigma_{2}$.

\section{Predesign Of Parabolic Function Of Transmission Errors}

The transmission function for an ideal gear train is linear and is represented as

$$
\phi_{2}=\frac{N_{1}}{N_{2}} \phi_{1}
$$


where $N_{i}$ is the number of gear teeth, $\phi_{i}$ is the rotation angle of the gear. Due to misalignment (change of crossing angle, change of shortest distance between the gear axes, etc.) the transmission function becomes a piecewise almost linear one with the period of transmission errors as the cycle of the meshing of a pair of teeth. Due to the jump of the angular velocity at the junction of cycles, the acceleration approaches to an infinite large value and causes large vibration.

The advanced design of low-noise spiral bevel gears proposed in this paper is based on application of a predesigned parabolic function of transmission errors with a controlled level of the maximal error. It has been shown in $[7,8]$ that a parabolic function can absorb a linear function and the resulting function of transmission errors will remain parabolic.

The predesigned parabolic function of transmission errors of spiral bevel gears and hypoid gears is provided by certain relationships between the curvatures of the contacting gear tooth surfaces. An alternative option applicable for all types of gears is the possibility to obtain a predesigned parabolic function by application of CNC machines.

\section{Direct Relations Between Principal Curvatures And Directions of Contact- ing Surfaces}

Henceforth, we will consider two cases of tangency of contacting surfaces: (i) the surface are in point contact at every instant (when the tangency of the pinion-gear tooth surfaces is discussed), and (ii) when the surfaces are in tangency along a line (when the generation of the pinion and gear tooth surfaces by the head-cutter is discussed).

The derivation of relations between the principal curvatures and directions for two surfaces being in continuous tangency is based on application of the following equations $[6,7]$ :

$$
\begin{gathered}
\mathbf{v}_{r}^{(2)}=\mathbf{v}_{r}^{(1)}+\mathbf{v}^{(12)}=v_{r}^{(1)}+v_{t r}^{(1)}-v_{t r}^{(2)} \\
\dot{\mathbf{n}}_{r}^{(2)}=\dot{\mathbf{n}}_{r}^{(1)}+\dot{\mathbf{n}}_{t r}^{(1)}-\dot{\mathbf{n}}_{t r}^{(2)}=\dot{\mathbf{n}}_{r}^{(1)}+\left(\omega_{t r}^{(1)}-\omega_{t r}^{(2)}\right) \times \mathbf{n}^{(1)}
\end{gathered}
$$




$$
\frac{d}{d t}\left[\mathbf{n}^{(1)} \cdot \mathbf{v}^{(12)}\right]=0
$$

The designation $\mathbf{v}_{r}^{(i)}$ and $\mathbf{v}_{t r}^{(i)}$ designate the linear velocity of a contact point that moves over the surface and with the surface, respectively. The subscripts " $r$ " and " $t r$ " indicate the relative motion and the transfer motion, respectively. The designation $\dot{\mathbf{n}}_{r}^{(i)}$ indicates the velocity of the tip of the unit contact normal in relative motion (over the tooth surface), in addition to the velocity of the unit normal in translational motion over the tooth surface. The designation $\dot{\mathbf{n}}_{t r}^{(i)}$ indicates the velocity of the tip of the unit contact normal in the rotational motion with the tooth surface, that is the transfer motion of the unit normal. Equation (8) is the differentiated equation of meshing.

Figure 3 shows the mean contact point $M$ and the unit vectors along the principal directions $\left(\mathbf{e}_{s}, \mathbf{e}_{q}\right)$ on surface $\Sigma_{2}$ and the unit vectors along the principal directions (eff, $\mathbf{e}_{h}$ ) on surface $\Sigma_{1}$. The above mentioned unit vectors are located in the plane that is tangent to the contacting surfaces at point $M$. The subscripts 1 and 2 for the contacting surfaces are tentative and may indicate the surfaces of the pinion and the gear, the generated surface and the generating surface.

We may transform the system of equations (6) to (8) taking into account Rodrigues's formula for principal curvatures and reducing the number of scalar equations and unknowns that can be obtained from the above mentioned equations. Finally, we will be able to obtain an overdetermined system of three equations in two unknowns of the following structure $[6,7]:$

$$
a_{i 1} v_{s}^{(1)}+a_{i 2} v_{q}^{(1)}=a_{i 3} \quad(i=1,2,3)
$$

Here,

$$
v_{s}^{(1)}=v_{r}^{(1)} \cdot e_{s} \quad ; \quad v_{q}^{(1)}=v_{r}^{(1)} \cdot e_{q}
$$

Coefficients $a_{i 1}, a_{i 2}$ and $a_{i 3}$ are expressed in terms of parameters of generation motion and principal curvatures $k_{s}, k_{q}, k_{f}, k_{h}$ and $\sigma^{(12)}$. The consideration of linear equation system (9) yields the following results $[6,7]$ : 
(i) The rank of the augmented matrix of the system is one in the case of line contact of the mating surfaces.

(ii) The rank of the augmented matrix is two in the case of surface point contact.

(iii) In case of line contact we will obtain three equations for the determination of $k_{f}, k_{h}$ and $\sigma^{(12)}$ in terms of $k_{s}, k_{q}$ and the parameters of motion.

(iv) In case of point contact we will obtain one equation of the following structure:

$$
F\left(k_{f}, k_{h}, \sigma^{(12)}, k_{s}, k_{q}, m_{21}^{\prime}\right)=0
$$

Two additional equations for the determination of $k_{f}, k_{h}$ and $\sigma^{(12)}$ may be obtained considering as given the direction of $v_{r}^{(1)}$ (the ratio $v_{s}^{(1)} / v_{q}^{(1)}$ ) and the magnitude of the major axis of the instantaneous contact ellipse.

The system of linear equations (9) must be applied two times: first for the determination, at point $M$, of the principal curvatures and directions of the pinion (considering the principal curvatures and directions of the gear as known); secondly for the determination of the principal curvatures and directions of the pinion head-cutter (using the obtained principal curvatures and directions of the pinion). Then the "best" machine-tool settings for the pinion generation will be obtained that determines the pinion tooth surface that will be "best" fitted to the gear tooth surface [9].

\section{Tooth Contact Analysis}

The simulation of meshing of pinion and gear tooth surfaces is based on the condition of continuous tangency of the pinion and gear tooth surfaces, and is represented in a fixed coordinate system $S_{h}$ (Fig. 4).

Using the condition of continuous tangency, we can obtain five independent nonlinear equations in six unkowns. One of the unknowns is chosen as the input one [4-9]. The continuous solution of the system of five nonlinear equations [10] permits the determination of the paths of contact on pinion (gear) tooth surfaces and the transmission errors. In addition, using the relations between the principal curvatures of the contacting surfaces, it becomes possible to determine the dimensions and orientation of the instantaneous contact ellipse and the bearing contact. 


\section{Numerical Example}

The numerical example to be shown is the same as the design tested in [11]. The blank data are shown in Table 1 and are the input for two computer programs: (i) for the determination of gear machine-tool settings and (ii) for the local synthesis program. The output for the local synthesis computer program are the pinion machine-tool settings. The gear and pinion machine-tool settings are represented in Tables 2 and 3, respectively. The machine-tool settings are the input for the developed TCA computer programs. The influence of misalignment was simulated by variation of settings $\mathrm{V}$ and $\mathrm{H}$ (Fig. 4) that represent the offset of the gear drive and the axial displacement of the pinion. The drive offset means that the axes of the rotation of the pinion and the gear are crossed but not intersected, and $E$ is the shortest distance bẹtween the crossed axes (Fig. 4). The output of the TCA program are the transmisssion errors and the bearing contact. Figures 5, 6, and 7 represent the TCA output for the three sets of settings $V$ and $H$.

The obtained results show that the transmission errors are very low (they do not exceed 8 arc second) and the bearing contact is very stable.

\section{Conclusion}

A methodology for the design of low-noise face-milled spiral bevel gear has been developed. The concept of a predesigned parabolic function of transmission errors that can absorb linear transmission errors caused by manufacturing and assembly has been investigated. Machine tool settings for the spiral bevel gear mesh system are calculated and numerically tested via the tooth contact analysis(TCA) that was developed during this study. From a numerical example, the tolerance of the chosen "best" machine tool settings to misalignment was determined. Misalignments were simulated numerically by displacing

the pinion axially and changing the gear offset from their nominal operating locations. The bearing contact remained on the active profile and the transmission error remained the preferred parabolic shape with the same level of error as when the gears operate at their nominal locations. 


\section{Acknowledgment}

The authors express their gratitide to Mr. Zachary Henry (Bell Helicopter Co. ), Mr. John Thomas (the Gleason Works), and Mr. David Lewicki (the NASA Lewis Research Center) for their encouragement in this research project and the experimental work for the gear drive with the new design.

TABLE 1 BLANK DATA(Length in Inch)

\begin{tabular}{|l|l|l|}
\hline & PINION & GEAR \\
\hline Number of Teeth & 19 & 62 \\
\hline Pressure Angle & & $20^{\circ}$ \\
\hline Shaft Angle & $95^{\circ}$ & \\
\hline Mean Spiral Angle & $35^{\circ}$ & \\
\hline Hand of Spiral & LH & RH \\
\hline Outer Cone Distance & & 5.21 \\
\hline Face Width & & 1.45 \\
\hline Whole Depth & 0.30 & 0.30 \\
\hline Clearance & 0.031 & 0.031 \\
\hline Addendum & 0.194 & 0.075 \\
\hline Dedendum & 0.106 & 0.225 \\
\hline Pitch Angle & $17^{\circ} 25^{\prime}$ & $77^{\circ} 35^{\prime}$ \\
\hline Root Angle & $16^{\circ} 34^{\prime}$ & $75^{\circ} 26^{\prime}$ \\
\hline Face Angle & $19^{0} 34^{\prime}$ & $78^{\circ} 26^{\prime}$ \\
\hline
\end{tabular}


TABLE 2 GEAR MACHINE TOOL SETTINGS

\begin{tabular}{|l|l|}
\hline Blade Angle & $20^{\circ}$ \\
\hline Cutter Diameter & 7.5 \\
\hline Point Width & 0.09 \\
\hline Radial Setting & 3.8561 \\
\hline Cradle Angle & $52.8084^{\circ}$ \\
\hline Machine Center to Back & 0.0 \\
\hline Sliding Base & -0.0333 \\
\hline Ratio of Roll & 1.0232 \\
\hline Blank Offset & 0.0 \\
\hline Machine Root Angle & $75.4333^{\circ}$ \\
\hline
\end{tabular}

TABLE 3 PINION MACHINE TOOL SETTINGS

\begin{tabular}{|l|l|l|}
\hline & Convex & Concave \\
\hline Cutter Blade Angle & $25^{\circ}$ & $15^{\circ}$ \\
\hline Cutter Point Radius & 3.5903 & 3.9163 \\
\hline Radial Setting & 4.1632 & 3.4909 \\
\hline Cradle Angle & $53.4881^{\circ}$ & $54.3468^{\circ}$ \\
\hline Machine Center to Back & 0.038 & -0.0489 \\
\hline Sliding Base & -0.0108 & 0.0139 \\
\hline Ratio of Roll & 3.4905 & 3.1034 \\
\hline Blank Offset & 0.4722 & -0.5208 \\
\hline Machine Root Angle & $16.5667^{\circ}$ & $16.5667^{\circ}$ \\
\hline
\end{tabular}




\section{References}

1. Litvin, F. L. and Go, K., 1964, "Improvement of Conditions of Meshing of Spiral Bevel Gears", Proceedings of Theory of Mechanisms and Machines, Academy of Sciences of USSR, No. 98- 99.

2. Baxter, M. L., 1973, "Exact Determination of Surfaces for Spiral Bevel Gears", Industrial Mathematics, Vol. 23, part 2.

3. Gleason Works, 1981, "Understanding Tooth Contact Analysis", Rochester, NY 14692, Publication No. SD 3139.

4. Wildhaber, E., 1946, "Basic Relationships of Hypoid Gears", American Machinist, Vol. 90, No. 4, pp. 108-111.

5. Litvin, F. L. and Gutman, Y., 1981, "Methods of Synthesis and Analysis for Hypoid Gear Drives of Formate and Helixform", ASME Journal of Mechanical Design, Vol. 103, pp. 83-113.

6. Litvin, F. L., 1989, "Theory of Gearing", NASA RP-1212, AVSCOM TR-88-035.

7. Litvin, F. L., "Gear Geometry and Applied Theory", Prentice Hall, in Press.

8. Litvin, F. L., et al., 1989, “ Topology of Modified Helical Gears”, Surface Topology, Vol. 2, No. 1, pp. 41-59.

9. Litvin, F. L. and Zhang, Y., 1991, "Local Synthesis and Tooth Contact Analysis of Face-Milled Spiral Bevel Gears", NASA CR-4342, AVSCOM TR-90-C-028.

10. IMSL MATH/LIBRARY, 1989, "User's Manual", IMSL(International Mathematics and Statistics Library) Inc., Houston.

11. Lewicki, D. L., Handschuh, R. H., Henry, Z. and Litvin, F. L., 1993, "Low-Noise, High-Strength, Spiral-Bevel Gears for Helicopter Transmissions", Proceedings of 29th Joint Propulsion Conference and Exhibit Cosponsored by the AIAA, SAE, ASME, and ASEE, Monterey, California, June 28-30. 


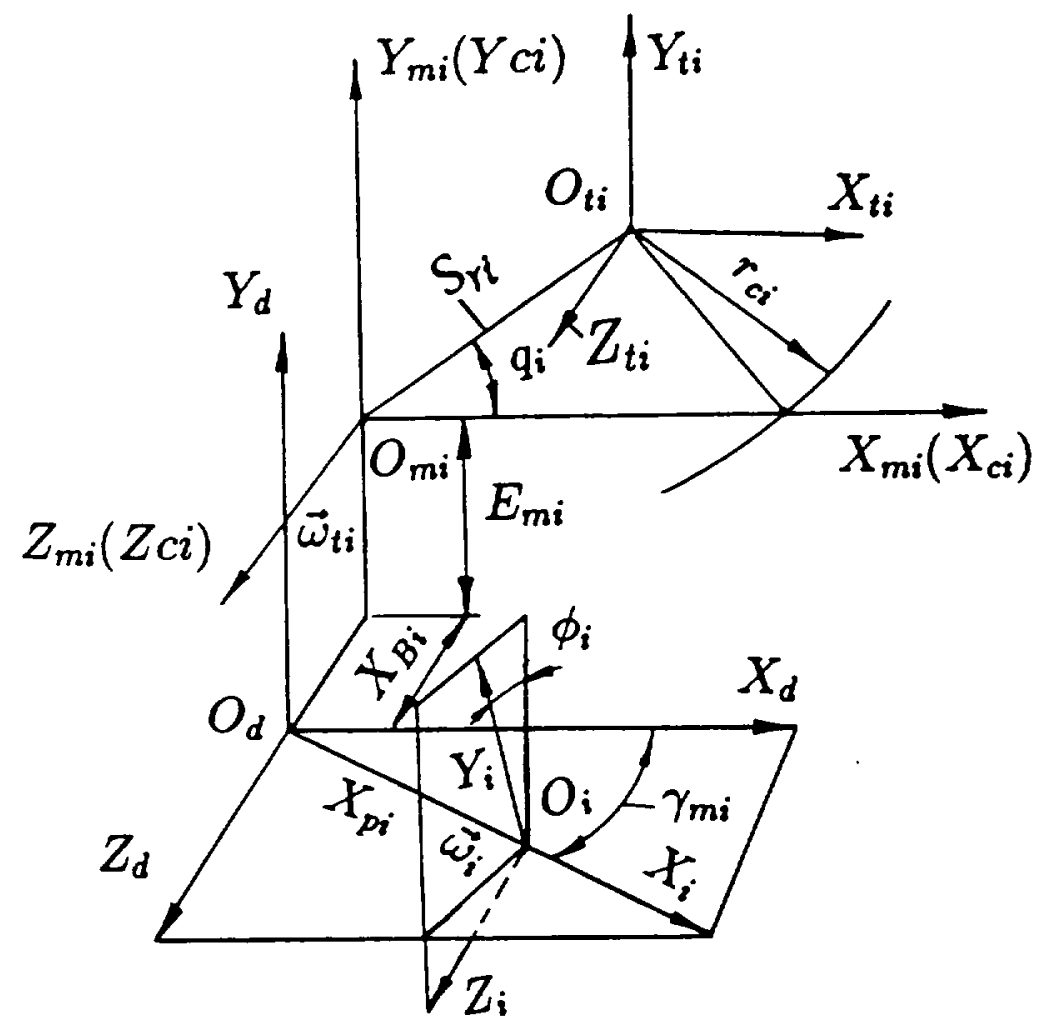

Fig. 1 MACHINE-TOOL SETTINGS FOR TOOTH GENERATION 


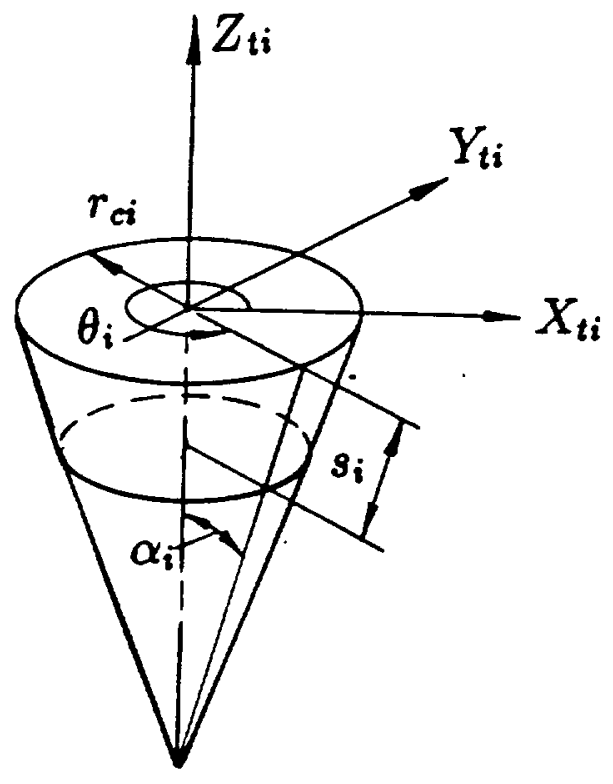

Fig. 2 TOOL GENERATING SURFACE 


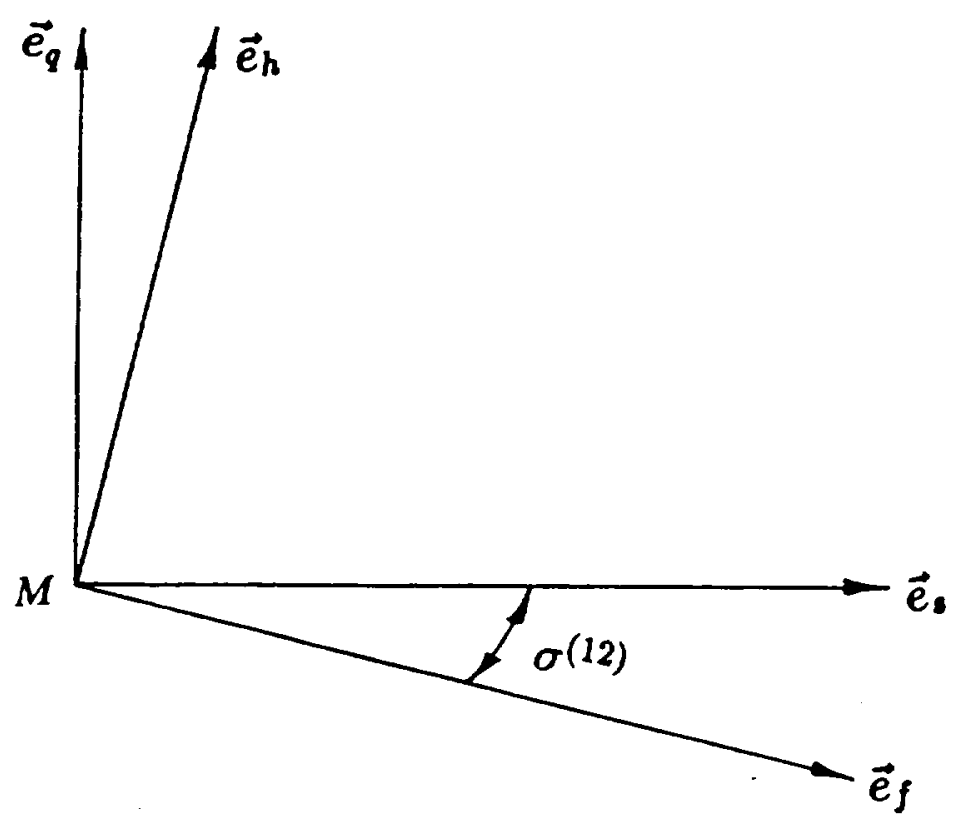

Fig. 3 PRINCIPAL DIRECTIONS OF CONTACTING SURFACES 


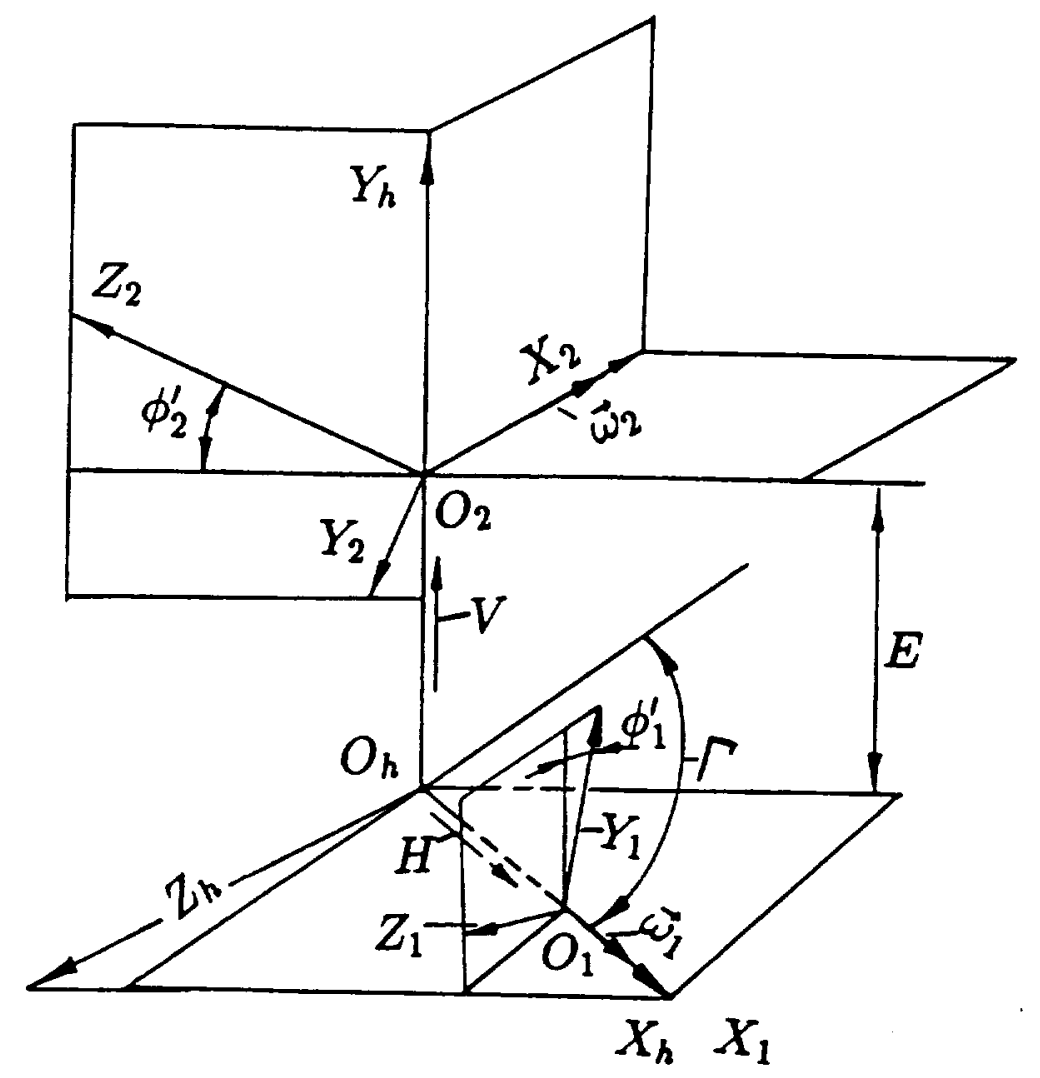

Fig. 4 COORDINATE SYSTEMS FOR TOOTH CONTACT ANALYSIS 


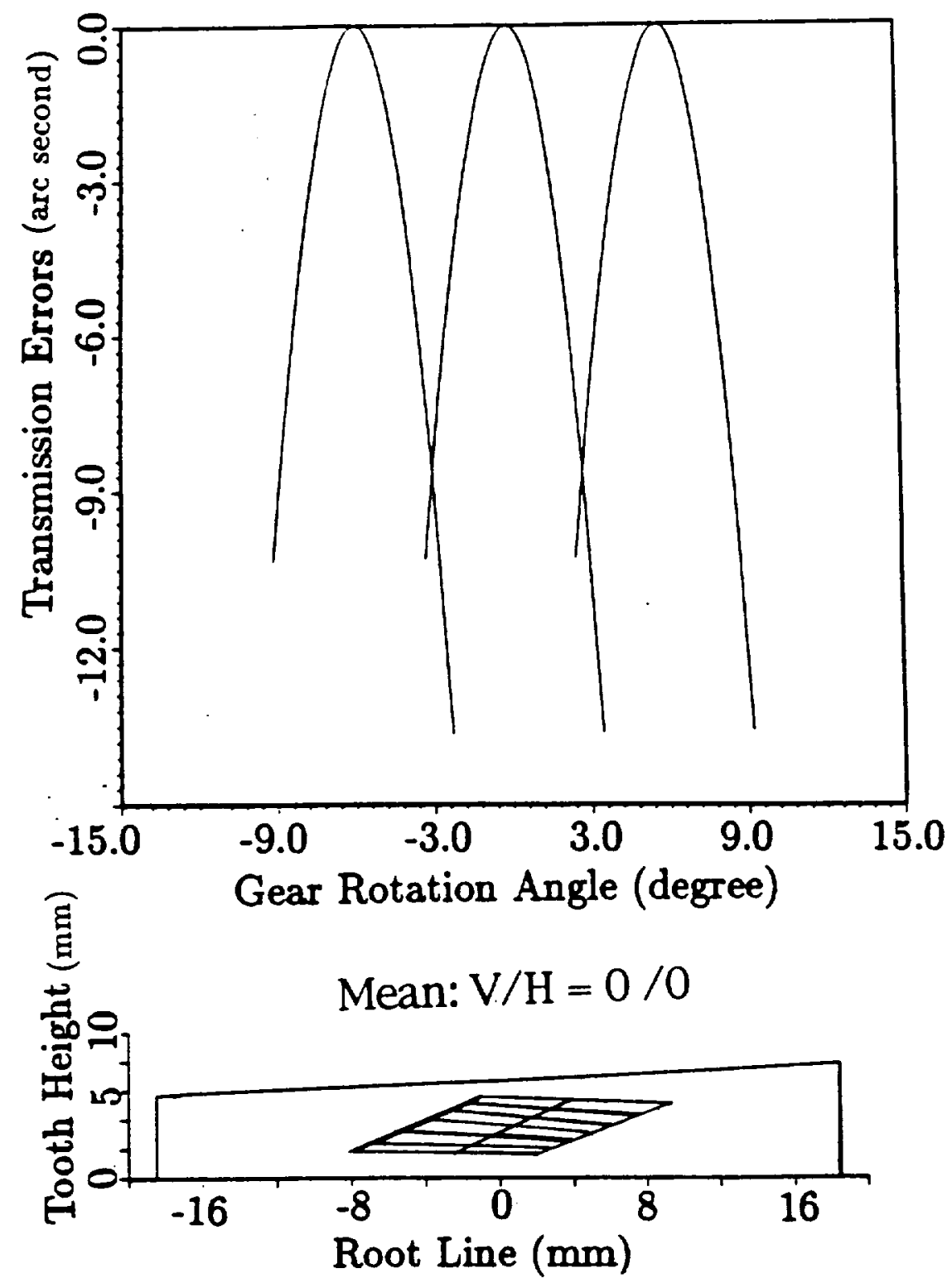

Fig. 5 TRANSMISSION ERRORS AND CONTACT PATTERN FOR MEAN POSITION 


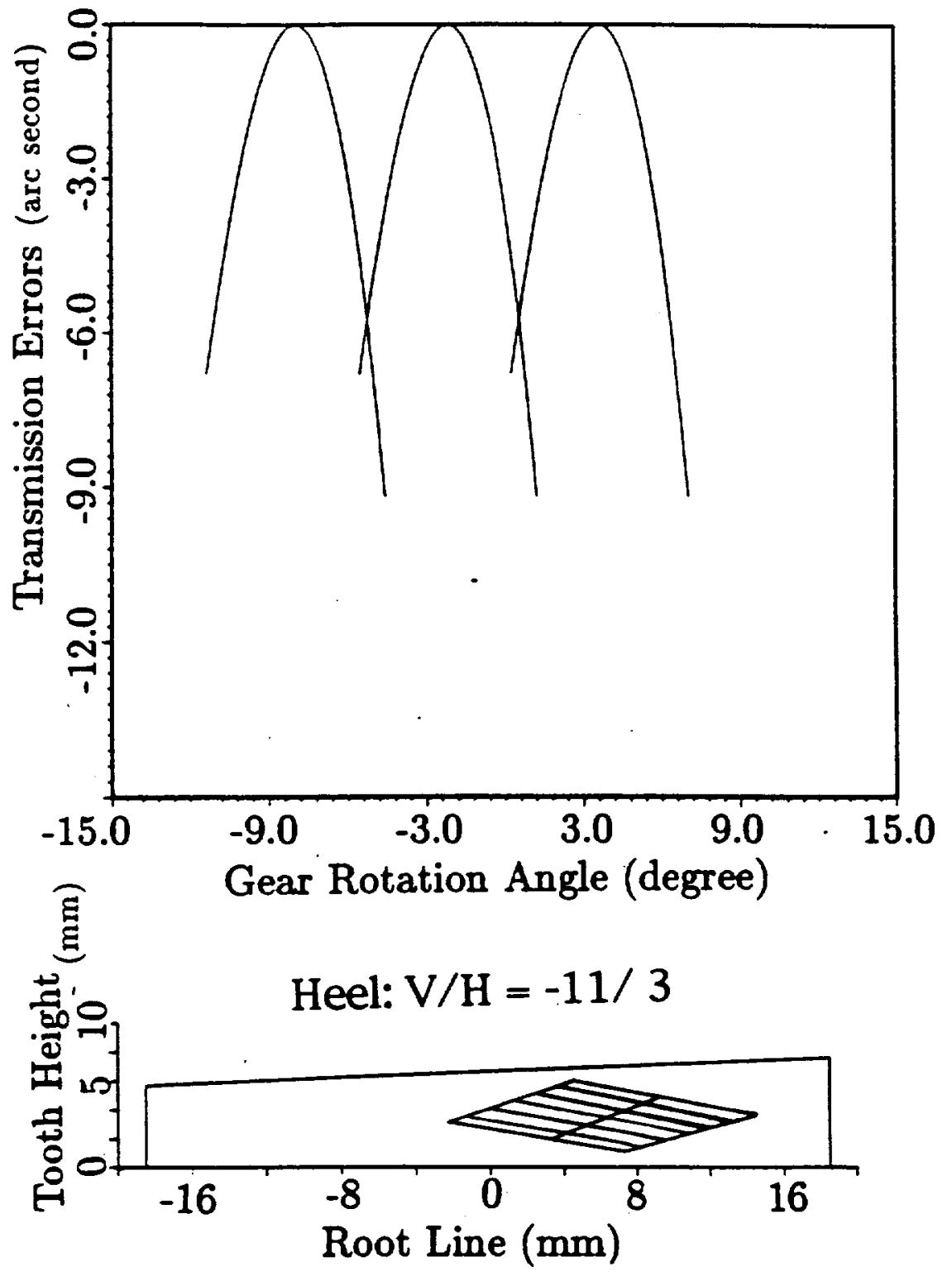

Fig. 6 TRANSMISSION ERRORS AND CONTACT PATTERN FOR HEEL POSITION 


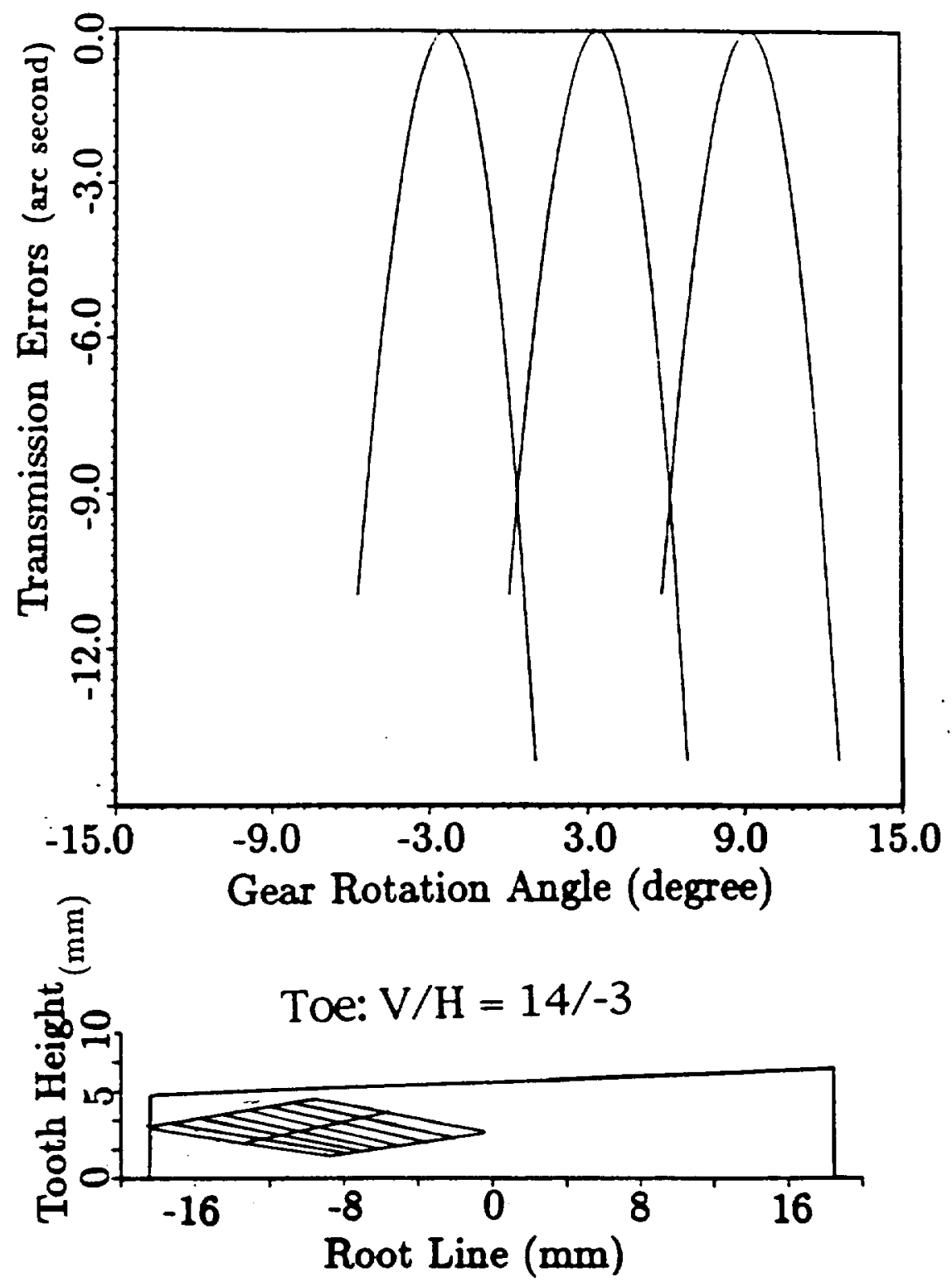

Fig. 7 TRANSMISSION ERRORS AND CONTACT PATTERN FOR TOE POSITION 
Public reporting burden for this collection of information is estimated 10 average 1 hour per response, including the fime for reviewing instructions, searching existing data sources, gathering and maintaining the data needed, and completing and reviewing the collection of information. Send comments regarding this burden estimate of any othef aspect of this collection of information, including sugestions 2202-4302, and to the Oftice of Management and Budget, Papenwork Reduction Projed (0704-0188), Washington, DC 20503.
1. AGENCY USE ONLY (Leave blank)
2. REPORT DATE
August 1994
3. REPORT TYPE AND DATES COVERED
Technical Memorandum
5. FUNDING NUMBERS

4. TITLE AND SUBTITLE

Computerized Design of Low-Noise Face-Milled Spiral Bevel Gears

6. AUTHOR(S)

WU-505-62-36

Faydor L. Litvin, Yi Zhang, and Robert F. Handschuh

1L162211A47A

7. PERFORMNG OAGAMIZATION NAME(S) AND ADDRESS(ES)

NASA Lewis Research Center

8. PERForming organization

Cleveland, Ohio 44135-3191

and

Vehicle Propulsion Directorate

REPORT NUMBER

U.S. Army Research Laboratory

Cleveland, Ohio 44135-3191

9. SPONSORING/MONITORING AGENCY NAME(S) AND ADDRESS(ES)

National Aeronautics and Space Administration

Washington, D.C. 20546-0001

and

U.S. Army Research Laboratory

Adelphi, Maryland 20783-1145

E-9078

10. SPONSORING/MONITOAING

AGENCY REPORT NUMBER

NASA TM-106713

ARL-TR-306

11. SUPPLEMENTARY NOTES

Prepared for the 23rd Mechanisms Conference sponsored by the American Society of Mechanical Engineers, Minneapolis, Minnesota, September 11-14, 1994. Faydor L. Litvin, University of Illinois at Chicago, Chicago, nlinois 60616; Yi Zhang, University of Michigan at Dearborm, Dearbom, Michigan

48823; Robert F. Handschuh, Vehicle Propulsion Directorate, U.S. Amy Research Laboratory, NASA Lewis Research Center. Responsible person,

Roben F. Handschuh, organization code 2730, (216) 433-3969.

12a. DISTAIBUTIONAVAILABILTTY STATEMENT

12b. DISTRIBUTION CODE

Unclassified - Unlimited

Subject Category 37

13. ABSTRACT (Maxlmum 200 words)

An advanced design methodology is proposed for the face-milled spiral bevel gears with modified tooth surface geometry that provides a reduced level of noise and has a stabilized bearing contact. The approach is based on the local synthesis of the gear drive that provides the "best" machine-tool settings. The theoretical aspects of the local synthesis approach are based on the application of a predesigned parabolic function for absorption of undesirable transmission errors caused by misalignment and the direct relations between principal curvatures and directions for mating surfaces. The meshing and contact of the gear drive is synthesized and analyzed by a computer program. The generation of gears with the proposed geometry design can be accomplished by application of existing equipment. A numerical example that illustrates the proposed theory is presented.

14. SUBJECT TERMS

15. NUMBER OF PAGES

Gears; Gear Teeth; Transmissions

16. PAICE CODE

A03

\begin{tabular}{c|c}
\hline 17. SECUATY CLASSIFICATION & 18. SECUATY CLASSIFICATION \\
OF REPORT & $\begin{array}{c}\text { OF THIS PAGE } \\
\text { Unclassified }\end{array}$
\end{tabular}

19. SECURITY CLASSIFICATION OF ABSTRACT

Unclassified 